\title{
Tuberculosis of Exceptional Location in a Haemodialysis Patient
}

\author{
Moussokoro Hadja Koné, Ibtissam Fares, Imane Houem, Loubna Benamar, \\ Naima Ouzeddoun, Rabia Bayahia, Tarik Bouattar \\ Unit of Nephrology, Dialysis and Renal Transplant, CHU Ibn Sina, Faculty of Medicine and Pharmacy, \\ Mohammed V University, Rabat, Morocco \\ Email: hadjamoussokoro@gmail.com
}

How to cite this paper: Koné, M.H., Fares, I., Houem, I., Benamar, L., Ouzeddoun, N., Bayahia, R. and Bouattar, T. (2019) Tuberculosis of Exceptional Location in a Haemodialysis Patient. Open Journal of Nephrology, 9, 35-39.

https://doi.org/10.4236/ojneph.2019.91004

Received: February 14, 2019

Accepted: March 25, 2019

Published: March 28, 2019

Copyright $\odot 2019$ by author(s) and Scientific Research Publishing Inc. This work is licensed under the Creative Commons Attribution International License (CC BY 4.0).

http://creativecommons.org/licenses/by/4.0/

\begin{abstract}
Background: Chronic haemodialysis patients present a lack of immunity responsible for a high incidence of tuberculosis of atypical and non-pulmonary localizations. Observation: We present a clinical case of a haemodialysis patient that presents an isolated localisation of prostate tuberculosis. He had no clinical signs but had laboratory findings of inflammatory syndrome and high Prostatic Antigen (PSA) level. The diagnosis was made by histopathologic study of the piece of prostatectomy. The patient received a six-month treatment with an initial two-month phase involving four anti-tuberculosis drugs (Rifampicin, Isoniazid, Ethambutol and Pyrazinamid) followed by a four-month maintenance phase involving two drugs (Isoniazid and Rifampicin). All drugs were adapted to his dialysis condition. We noticed no side effects of drugs. Conclusion: Clinical signs of prostatic tuberculosis are not specific, mainly made of an obstructive symptom. The diagnosis of prostatic tuberculosis is based on a bundle of clinical and biological arguments. Koch Bacilli (KB) can rarely be found in urine or sperm. In haemodialysis patient, it can be masked by non specific aspect of inflammatory syndrome. The management must be adjusted and a close following up of side effects is necessary.
\end{abstract}

\section{Keywords}

Tuberculosis, Prostatitis, Dialysis, Inflammatory Syndrome

\section{Introduction}

Chronic haemodialysis patients present a reduced immunity responsible for a high incidence of tuberculosis. Clinical presentation is often atypical and non-pulmonary localisations are not uncommon. However, isolated prostate tu- 
berculosis, as in the general population, remains exceptional. We report the case of a patient undergoing chronic heamodialysis who had an isolated prostate tuberculosis discovered incidentally during his renal transplant checkup.

\section{Observation}

Mr. E. M aged 52 years, of middle income level, of a Moroccan origin, is followed in our unit as a candidate for renal transplant. He is a former smoker with polycystic kidney disease undergoing hemodialysis since 2008.

The general condition of the patient was preserved and the renal pre-transplant workup revealed a high C Reactive Protein (CRP): $30 \mathrm{mg} / \mathrm{l}$, without leukocytosis or lymphopenia. The Prostatic Specific Antigen (PSA) was high at $7 \mathrm{ng} / \mathrm{ml}$. The bacteriologic analysis of urine found leukocytes without any growth and specificaly no Koch Bacilli (KB) in the urine. Digital rectal examination revealed a soft prostate, homogeneous and non tender.

Prostate MRI showed a left peripheral nodule of $8 \times 6 \mathrm{~mm}$. We carried out prostate biopsy but the histopathologic study had not been able to differanciate prostate carcinoma from prostate tuberculosis. In the context of renal transplant project, no other paraclinical exploration has been made and a radical prostatectomy has been carried out. The histopathologic study was in favor of an epithelioid and giant-cell granulomatous prostatitis with caseous necrosis that allowed us to retain the diagnosis of prostate tuberculosis.

There was no sexual transmitted infection, and the serology for Human Immunodeficiency Virus was negative. The search of another tuberculosis location, particularly pulmonary, urinary or bone location, was negative. Our patient received a six-month treatment with an initial two-month phase involving four anti-tuberculosis drugs (Rifampicin, Isoniazid, Ethambutol and Pyrazinamid) followed by a four-month maintenance phase involving two drugs (Isoniazid and Rifampicin).

The evolution after one year was marked by the absence of the inflammatory syndrome, of high PSA rate and leukocytes rate in urine. The patient had maintained postoperative urinary incontinence, cured after multiple bladder rehabilitation sessions.

Renal transplant was allowed 12 months after the end of the treatment and the patient has been placed on the national list of candidates for renal transplant by brain-dead donor.

\section{Discussion}

In the general population, isolated prostate tuberculosis is rare. Some cases are described in the literature. Between 1989 and 2004, during a Moroccan study, Bensouda et al. noted of 22 patients with genital tuberculosis only one case of prostatic tuberculosis [1].

For patients undergoing chronic hemodialysis, the risk of tuberculosis infections has a prevalence of 9.43\% [2]. These infections present in extra-pulmonary form in 52\% [3] to 77\% [4] of the cases in Indian and Saudi studies. The geni- 
to-urinary location is $11 \%$ in the Saudi study [4], one case of isolated prostatic location was noticed.

Tuberculosis infection of the prostate is primarily hematogenous, and not necesarly associated with urinary lesions. Nevertheless a sexual transmission is possible and has been described. The hypothesis of dissemination after BCG therapy has also been reported [1]. Clinical manifestations are not very specific, mainly made of an obstructive symptom [5]. Our patient did not have any clinical manifestations and no other tuberculosis localization was found.

Rectal examination often shows an increase in prostate volume, with an elastic, firm, nodular or stony consistency. PSA level [6] [7] is high with an inflammatory syndrome, as illustrated by our case. The presence of Koch Bacilli (KB) is inconsistent in the urine as well as in the semen. The search for KB in the urine was negative in our patient. Ultrasound prostatic morphology is also unspecific. In our case, as part of the renal transplant checkup, a prostate MRI was performed. The Polymerase Chain Reaction (PCR) and Quantiferon (Elisa) promise interesting results for the diagnosis of tuberculosis in dialysis patient, but there is currently no consensus, particularly in terms of positivity threshold [8]. They were not carried out for our patient.

Histology responds to two mechanisms. Cavities are formed by the caseus and end up by creating perineal fistulas. Fibrosis, limiting the extension of the lesions, is responsible for the clinical signs of obstruction such as dysuria and pollakiuria [5]. For our patient, the results of the prostate biopsy were not conclusive: there was a doubt between a prostatic tuberculosis and a prostatis carcinoma. The diagnosis was then found on the radical prostatectomy. There were foci of epithelioid and giant-cell granuloma with a pathognomonic necrosis of tuberculosis.

The treatment of tuberculosis in the dialysis patient must be adapted to the dialysis conditions. The treatment duration is the same as in subjects with normal renal function.

This treatment should involve several antituberculosis drugs, in two phases, with a regular single intake on an empty stomach in the morning, for a sufficient duration, 06 months. The pattern adopted according to the resistance profiles comprises the association of Isoniazid (I), Rifampicin (R), Pyrazinamide (P) and Ethambutol (E) [9]. The dosage adaptation used for our patient is detailed in Table 1 [10]. For the haemodialysis patients, the association ERIP should be taken 6 hours prior to the onset of hemodialysis sessions, and RI at the same hour on non-dialysis days during the initial 2-month phase. To end the treatment, the association RI should be taken daily for 4 months in the maintenance phase.

The Monitoring of residual levels of anti-tuberculosis drugs can be performed for optimal dose adaptation in the hemodialysis patient. Table 2 summarizes the therapeutic gap of first line anti-tuberculosis drugs [11].

The treatment toxicity is more pronounced in dialysis patients compared with patients not yet on dialysis. Hepatic and neurological toxicities are the most 
Table 1. Adaptation of anti-tuberculosis drugs according to creatinin clearance.

\begin{tabular}{|c|c|c|c|c|c|c|}
\hline \multirow{2}{*}{$\begin{array}{l}\text { Creatinin } \\
\text { clearance } \\
(\mathrm{ml} / \mathrm{min})\end{array}$} & \multirow{2}{*}{ Rifampicin } & \multirow{2}{*}{ Isoniazid } & \multirow{2}{*}{ Ethambutol } & \multirow{2}{*}{ Pyrazinamid } & \multicolumn{2}{|c|}{ Rifabutin } \\
\hline & & & & & $>50 \mathrm{~kg}$ & $<50 \mathrm{~kg}$ \\
\hline $60-30$ & $10 \mathrm{mg} / \mathrm{kg} /$ day & 3 to $5 \mathrm{mg} / \mathrm{kg} /$ day & $20 \mathrm{mg} / \mathrm{kg} /$ day & $30 \mathrm{mg} / \mathrm{kg} / 2$ days & $300 \mathrm{mg} /$ day & $450 \mathrm{mg} / 2$ days \\
\hline $30-15$ & 10 mg/kg/day & 3 to $5 \mathrm{mg} / \mathrm{kg} /$ day & $20 \mathrm{mg} / \mathrm{kg} / 2$ days & $30 \mathrm{mg} / \mathrm{kg} / 2$ days & $300 \mathrm{mg} /$ day & $450 \mathrm{mg} / 2$ days \\
\hline$<15$ et $\mathrm{HD}$ & $\begin{array}{c}10 \mathrm{mg} / \mathrm{kg} / \text { day } \\
\text { Non dialyzable }\end{array}$ & $\begin{array}{c}3 \text { to } 5 \mathrm{mg} / \mathrm{kg} / \text { day } \\
\text { Dialysable }\end{array}$ & $\begin{array}{c}20 \mathrm{mg} / \mathrm{kg} / 2 \text { days } \\
\text { Dialysable }\end{array}$ & $\begin{array}{c}30 \mathrm{mg} / \mathrm{kg} / 2 \text { days } \\
\text { Dialysable }\end{array}$ & $\begin{array}{c}150 \mathrm{mg} / \text { day } \\
\text { Non dialysable }\end{array}$ & $\begin{array}{c}150 \mathrm{mg} / \text { day } \\
\text { Non dialysable }\end{array}$ \\
\hline CAPD & $10 \mathrm{mg} / \mathrm{kg} /$ day & 3 to $5 \mathrm{mg} / \mathrm{kg} /$ day & $20 \mathrm{mg} / \mathrm{kg} / 2$ days & $30 \mathrm{mg} / \mathrm{kg} / 2$ days & ND & ND \\
\hline
\end{tabular}

HD: Haemodialysis, CAPD: Continuous Ambulatory Peritoneal Dialysis, ND: Non Disponible.

Table 2. Therapeutic ranges for first-line anti-tuberculosis drugs.

\begin{tabular}{cccc}
\hline Molecules & $\begin{array}{c}\text { Interval between taking and dosing } \\
\text { (hour) }\end{array}$ & $\begin{array}{c}\text { Target serum concentrations (mg/l) } \\
\text { Ethambutol }\end{array}$ & $\begin{array}{c}\text { Concentration requiring } \\
\text { therapeutic adjustment (mg/l) }\end{array}$ \\
\hline Rifampicin & $2-3$ & $2-6$ & $<2$ \\
Isoniazid & $1-2$ & $8-24$ & $<6$ \\
Pyrazinamid & $1-2$ & $20-40$ & $<2$ \\
\hline
\end{tabular}

encountered. Neurological toxicity is efficiently prevented by the addition of systematic Pyridoxine to the dosage of 10 to $50 \mathrm{mg} / \mathrm{kg} / \mathrm{day}$. Liver fonction test must be performed at least monthly to detect a cytolysis or cholestasis that will require therapeutic facilities.

We did not notice any side effects of the treatment given to our patient.

\section{Conclusions}

Tuberculosis in dialysis patients has specific aspects concerning both the diagnosis and the treatment.

Atypical forms are not uncommon. In the face of any alteration of the general condition or inflammatory syndrome, even insidious of the dialysis patients, the diagnosis of tuberculosis must be mentioned.

The implementation of adequate therapy requires the monitoring of side effects that could involve the patient's vital and/or functional prognosis.

\section{Consent Statement}

I confirm that the patient had given his consent for the Case reports to be published.

\section{Conflicts of Interest}

The authors declare that they have no conflict of interest.

\section{References}

[1] Bensouda, A. and Hachimi, M. (2007) La tuberculose génitale: A propos de 22 cas. 
African Journal of Urology, 13.

[2] Al-Efraij, K., Mota, L., Lunny, C., Schachter, M., Cook, V. and Johnston, J. (2015) The Union Risk of Active Tuberculosis in Chronic Kidney Disease: A Systematic Review and Meta-Analysis. International Journal of Tuberculosis and Lung Disease, 19, 1493-1499. https://doi.org/10.5588/ijtld.15.0081

[3] Manmadha Rao, T., Ram, R., Swarnalatha, G., Santhosh Pai, B.H., Ramesh, V., Shyam Sunder Rao, C., Diwaker Naidu, G. and Dakshinamurty, K.V. (2013) Tuberculosis in Haemodialysis Patients: A Single Centre Experience. Indian Journal of Nephrology, 23, 340-345.

[4] Abdelrahman, M., Sinha, A.K. and Karkar, A. (2006) Tuberculosis in End-Stage Renal Disease Patients on Hemodialysis. Hemodialysis International, No. 10, 360-364. https://doi.org/10.1111/j.1542-4758.2006.00130.x

[5] Benchekroun, A. (2003) La tuberculose prostatique: A propos de 2 cas. Annales d urologie, 37, 120-122. https://doi.org/10.1016/S0003-4401(03)00032-9

[6] Rabesalama, S.S.E.N., Rakoto-Ratsimba, H.N., Rakototiana, A.F., Razafimahatratra, R., Raherison, R.A., Rantomalala, H.Y.H. and Randrianjafisamindrakotroka, N.S. (2010) Tuberculose Prostatique isolée. A propos d'un cas à Madagascar [Isolated Prostate Tuberculosis. Report of a Case in Madagascar]. Progrès en Urologie, 20, 314-316. https://doi.org/10.1016/j.purol.2009.06.004

[7] Sallami, S., Mejri, R., Chelif, M., Ben Salah, I., Ben Rhouma, S., Hafsia, G., Nouira, Y., Berais, N. and Horchani, A. (2009) La Tuberculose Prostatique Isolée. La Tunisie Médicale, 87, 407-408.

[8] Diel, et al. (2008) Predictive Value of a Whole Blood INF- $\gamma$ Assay for the Development of Active Tuberculosis Disease after Recent Infection with Mycobacterium tuberculosis. American Journal of Respiratory and Critical Care Medicine, 177, 1164-1170.

[9] Fraisse, P., Barnig, C. and Bazin, D. (2012) Traitement de la tuberculose maladie dans les populations particulières. La Lettre du Pneumologue, 15, 26-31.

[10] La Lettre d'ICAR. Maniement des médicaments antituberculeux chez le patient insuffisant rénal.

[11] Harcouët, L. and Tod, M. (2007) Intérêt du suivi thérapeutique des antituberculeux chez l'adulte. La Lettre de I Infectiologue, Tome, 22, 134-142. 